\title{
Prenatal Outcomes of Monochorionic Pregnancies: Complications, Management and Morbility
}

\author{
Research Article
}

Elga Lopez Gonzalez

Department of Gynecology and Obstetrics, Juan Ramon Jimenez, Huelva, Spain Hospital, Spain.

\section{Abstract}

Objective: The objetive in this study was to evaluate the incidence and complications of monochorionic twin.

Material and Methods: A retrospective study of 32 pregnancies twins monochorionic, a total of 8000 births, controlled Unit Prenatal Diagnosis and Obstetric Area Hospital Juan Ramon Jimenez, where chorionicity was found based on the sonographic features standard and all with the same team ultrasonographic (Voluson 730 Expert).

We analyzed fetal complications during pregnancy: Those that have required invasive treatment and hospitalization as well as termination of pregnancy. Patients requiring laser treatment or other management technique fetoscopic were referred to the Hospital Virgen de las Nieves in Granada. The statistical analysis of the variables was performed using the chi-square test for qualitative variables, defining the statistical significance for $\mathrm{p}<0.01$ value.

Results: The incidence of monochorionic twin pregnancies in the analyzed period was $21.3 \%$ of twin gestations. Maternal age 17-36 was between years, with an average of $28.97 .35 .5 \%$ of monochorionic twin pregnancies presented complications. No cases of anemia-polycythemia sequence (SAP) was observed and only one presented jarring malformation (no skull). The syndrome fetal-fetal transfusion (TTTS) was diagnosed in $16.1 \%$ of cases, performing laser coagulation of placental anastomoses in all of them and selective feticide and subsequent invasive procedure in severe CIR at week 22. In our population 3 cases of ntrauterine growth restriction selective (RCIUs) $(9.7 \%)$ were observed. The overall rate of prematurity was $64.5 \%$, and $100 \%$ for complicated monochorionic gestations. The overall survival rate was $83.9 \%$, and $54.5 \%$ for complicated monochorionic gestations. Comparing the survival rate and the overall rate of preterm birth, with the complicated pregnancies a statistically significant difference $(\mathrm{p}<0.01)$ was found with a contingency coefficient of 0.5 .

Conclusions: The incidence of complications in our sample is close to that described in the literature, despite attend a different demographics. The monochorionic twin pregnancy is a type of high-risk twin pregnancy, fetal associated with more complications, which we have observed that predict a high rate of morbidity and mortality. Early diagnosis and proper treatment of the same determine the evolution.

Keywords: Monochorionic Diamniotic Twin Pregnancy; Perinatal Morbimortality; Prenatal Diagnosis.

\section{Introduction}

Twin pregnancies have a higher rate of perinatal complications than singleton pregnancies, one of the causes of increased consumption of health resources due to the increase associated with recent use of assisted reproduction [1]. In the last 10 years higher rate of perinatal complications has a significant change in our concepts of multiple gestation derived from the development in knowledge about monochorionic twin pregnancy and is currently unacceptable to speak of twin pregnancy without specifying just chorionicity.
The monochorionic and dichorionic twin pregnancy represent completely different entities, they share some maternal and obstetric risks, but the type and severity of fetal pathology associated is markedly independent.

The incidence of multiple gestations has increased dramatically over the past two decades. The actual incidence, which currently accounts for $1-2 \%$ [2] of all pregnancies, a percentage that varies markedly in different areas according to the spread of reproduction techniques.

\footnotetext{
*Corresponding Author:

Elga Lopez Gonzalez,

Department of Gynecology and Obstetrics, Juan Ramon Jimenez, Huelva, Spain Hospital, Spain

Tel: 647509546

E-mail: elga_t@hotmail.com
}

Received: May 31, 2016

Accepted: July 13, 2016

Published: July 19, 2016

Citation: Elga Lopez Gonzalez (2016) Prenatal Outcomes of Monochorionic Pregnancies: Complications, Management and Morbility. Int J Reprod Fertil Sex Health, S1:004, 17-21. doi: http://dx.doi.org/10.19070/2377-1887-SI01004

Copyright: Elga Lopez Gonzalez ${ }^{\circ}$ 2016. This is an open-access article distributed under the terms of the Creative Commons Attribution License, which permits unrestricted use, distribution and reproduction in any medium, provided the original author and source are credited. 
The twin pregnancy is classified according to zygosity and chorionicity, although perinatal outcomes regarding all that is relevant is the chorionicity (3.4). Approximately $66 \%$ of twin pregnancies are dizygotic spontaneous, so that originate from two fertilized oocytes and, by definition, are dichorionic. The other third are monozygotic twins, usually referred to as identical twins come from one fertilized egg that has split after fertilization. The exact timing of this division determines important differences.

Regarding the type of placentation approximately $70 \%$ of monozygotic pregnancies are monochorionic and $30 \%$ are dichorionic [3]. Within 99\% monochorionic pregnancies are diamniotics and the remaining $1 \%$ is distributed between monoamniotics, mostly, and the uniqueness of the Siamese twins (Figure 1).

The monochorionic pregnancy presents a complication rates that are higher that those with dichorionic twins, and evidently to those in singleton pregnancies, with mortality 2-3 times higher in monochorionic [5] and a percentage of neurological injury $3 \%$ in dichorionic twins versus $30 \%$ in the monochorionic [6], explaining this high morbidity by the existence of a shared circulation through the placental vascular anastomoses. The connection between the two fetal circulations may be higher or lower, but there is always a vascular connection between the two systems, which will condition fetal risk abnormally high with respect to bichorial placentation [4]. But this basic requirement other conditioned by the unequal sharing of the placenta and the increased incidence of malformations meet.

Monochorionic gestations are at increased obstetrical and perinatal risk than dichorionic Monochorionic twins poses a greater risk of stillbirth, fetal loss before 24 weeks, intrauterine growth retardation and neurodevelopmental disorders during childhood [7, 8].

This is because the characteristic of any multiple pregnancy complications, monochorionic gestations added diamniotic specific complications such as fetal syndrome - twin transfusion syndrome (TTTS), which occurs in $10-15 \%$ of cases anemia sequence policitemia (SAP) by $5 \%$ of cases, selective intrauterine growth retardation ( RCIUs) by $10-15 \%$, stillbirths and a single sequence twin reversed arterial perfusion sequence or TRAP [9-16].
The aim of this study is to study the incidence and management of own fetal complications of monochorionic biamniotic twins.

\section{Material and Method}

A retrospective study 32 diamniotic monochorionic twin pregnancies from a total of 8000 , controlled in Prenatal Diagnosis Unit of Juan Ramon Jimenez between 2011-2013. During this period a total of 186 twin pregnancies were recorded.

For the diagnosis of chorionicity, sonographic criteria standards of the first trimester [17] were followed. Sonographic evaluation was performed between weeks 11 and 14, and was diagnosed as monochorionic diamniotics pregnancies those in which the presence of sign "T" sonographic and no sign "lambda" was observed, which is the most accurate dichorionic indicator and It corresponds to a triangular image formed by the separation of a wide interfetal septum in contact area with the trophoblast [18]. Ultrasound examination was performed every 2 weeks from week 16 , except in cases where fetal complications requiring appeared closer sonographic control.

We analyzed fetal complications during pregnancy, those that have required invasive treatment, hospitalization and pregnancy termination.

A comparative study was done by setting the difference between the rate of complications of monochorionic pregnancies in our population on a standard population through bibliographic reference data.

TTTS was defined as the presence of oligohydramnios sequence /severe Polyhydramnios in a monochorionic pregnancy, in which the receiver had Polyhydramnios and distended bladder, with maximum vertical column (MCV) amniotic $>8$ liquid or $10 \mathrm{~cm}$ depending on the age gestational, and the donor showed oligo / anhi-dramnios and collapsed or unidentifiable bladder [10]. TTTS cases were classified according to the stages of Quintero [10]:

- $\quad$ Stage I: TTTS criteria visible in the donor fetus during the entire examination bladder.

Figure 1. Bassett JM: Current perspectives on placental development and its integration Proc Nutr Soc .19991.

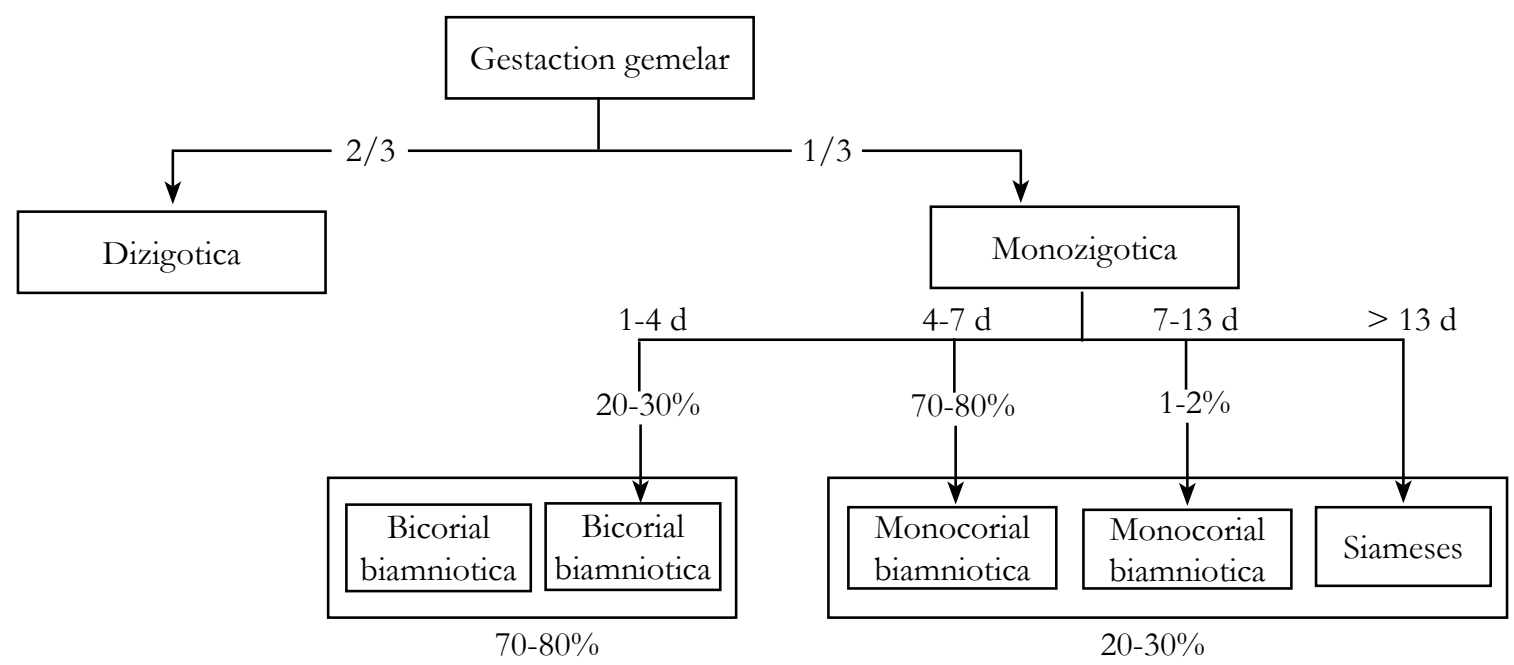


- $\quad$ Stage II: the bladder is not identified in the donor, which appears "stuck" to the uterine wall due to oligohydramnios (stuck twin).

- $\quad$ Stage III: abnormal Doppler critical or severe in either of the 2 twins with absent or reversed diastolic flow in the umbilical artery (usually donor) or absence or reversal of flow during atrial contraction in the ductus venosus, or presence pulsation in the umbilical vein (usually receptor).

- $\quad$ Stage IV: fetal hydrops, with signs of heart failure (usually receptor).

- $\quad$ Stage V: resulted in death of one or both fetuses.

The RCIUs was defined as the occurrence of a difference in the estimated fetal weight (PFE) of both fetuses each other $\geq 25 \%$, based on the weight of the older twin, with PFE lower twin below the 10th percentile, and no signs of TTTS [13].

The SAP diagnosis was made based on the Doppler peak systolic in (PVS-ACM) middle cerebral artery of both twins, which was fulfilled: first fetus: PVS-ACM $>1.5 \mathrm{MoM}$; and second fetus: PVS-ACM $<0.5 \mathrm{MoM}$, in the absence of polyhydramnios-oligohydramnios [12].

Stillbirths (IUFD) that spontaneous fetal deaths was considered, excluding stillbirths in lower gestational age at 20 weeks.

The rate of fetal survival was defined as the number of live births to 10 minutes of life.

The patients who had complications requiring laser treatment or other management technique fetoscopic, were referred to the Fetal Medicine Unit of Virgen de las Nieves Hospital in Granada.

Information regarding pregnancy and perinatal outcome was obtained from medical records and databases of the Prenatal Diagnosis Unit, as well as the internal database (History Obstetric computerized)

The statistical analysis was performed on the Biostatistics Unit of our hospital. Chi-square test for quantitative variables were applied. Statistical significance for $\mathrm{p}<0.01$ value was defined. $\mathrm{V}$ SPSS program was used. 9.0. The effect size was measured using the contingency coefficient, considering values $<0.3$ as low, medium and between $0.3-0.5>0.5$ high.

\section{Results}

The incidence of monochorionic diamniotic twins in the analyzed period was $17 \%$ of twin gestations. Maternal age was between 15 and 41 years, with an average of 31 years. $28 \%$ of monochorionic twin pregnancies had at least one fetal complications, which are specified in Table 1. We found in our series no case of SAP.

STFF was diagnosed in 5 cases $(16.1 \%)$. At the time of diagnosis, according to the classification in stages of Quintero, they were presented at the time of diagnosis in stage II. Laser coagulation vascular anastomoses was the most used option carried out in all cases in all cases and a only selective feticide.

In our series, 3 cases $(9.7 \%)$ of RCIUs were observed. Gestational age at diagnosis, the percentage of discordance PFE, Doppler study at that time and the estimation of amniotic fluid is detailed in (Table 2).

In cases of RCIUs, he acted expectantly when the Doppler study remained within normal limits in successive controls, and gestations in previable situation or high pre-maturity. The frequency of ultrasound examinations was individualized and the end time of gestation in each case.

Regarding fetal mortality were 3 fetal deaths in utero (IUFD); 1 with 31 weeks with symptomatic polyhydramnios that precise Amniodrenaje, an other one with 27 weeks which needed laser ablation by a fetal-fetal transfusion in a acraneo fetus, only malformation detected in our sample and finally another to 23 weeks, with no other compliaciones to report.

The overall rate of fetal survival in monochorionic pregnancies was $85 \%$. In monochorionic pregnancies with a fetal complication, this rate decreased to $76 \%$, with a statistically significant difference $(\mathrm{p}<0.01)$.

\section{Discussion}

Monochorionic twin pregnancies are associated with a higher rate of fetal complications compared with dichorionic twin pregnancies (7.8). In our series, $28.8 \%$ of monochorionic pregnancies had at least one complication, similar to $26 \%$ published by Lewi et al., [19] rate. Rates of specific complications of our cases were also

Table 1. Fetal Complications.

\begin{tabular}{|c|c|c|c|}
\hline & Casos & $\mathbf{\%}$ & \% reference $\mathbf{( *}^{*}$ \\
\hline STFF & 5 & $16.1 \%$ & $10-15 \%$ \\
\hline RCIUs & 3 & $9.7 \%$ & $15 \%$ \\
\hline MFIU & 3 & $9.7 \%$ & $2.1 \%$ \\
\hline MALFORMATION & 1 & $3.2 \%$ & $3 \%$ \\
\hline SAP & 0 & & $3-5 \%$ \\
\hline
\end{tabular}

(*):14. Lewi L, et al. Monochorionic diamniotic twins: complications and management options. Curr Opin Obstet Gynecol 2003; 15(2): 177-94.

15. Yamamoto M, GE, Ville Y. Transfusión feto-fetal. En:Medicina Fetal. E.Gratacos, R.Gomez, K.Nicolaides, R. Romero, L.Cabero. Ed.Médica Panamericana, Madrid, 2007. 
Table 2. Cases of RCIUs in our area. Description of GE: Gestacional Age, AFTD: absence telediastolic flow DV: Ductus venosus, OA: oligohydramnios.

\begin{tabular}{|c|c|c|c|}
\hline GE & DOPPLER & EG FINALIZATION & AMNIOTIC FLUID \\
\hline 21 & $\begin{array}{c}\text { AFTD } \\
\text { DV patology }\end{array}$ & 32 & OA/NORMAL \\
\hline 34 & normal & 34 & NORMAL \\
\hline 35 & DV patology & 35 & NORMAL \\
\hline
\end{tabular}

similar to those reported by other studies [19-21].

Except for the absence of anemia polycythemia syndrome in our population and the high rate compared with the standard population of intrauterine mortality, the rate of complications both individual and global resembles the standard population.

Complicated cases of our series with TT'TS had a higher rate of perinatal morbidity and mortality compared to those who passed normally. The mortality rate in pregnancies with TTTS is higher than in uncomplicated monochorionic pregnancies and complicated with other diseases $[5,6]$.

The treatment of choice is laser coagulation of placental anastomoses via fetoscopic, which removes interfetales anastomosis and reverses the haemodynamic process [19-22]. Preoperative evaluation of the location of the placenta is essential to decide the entry point depending on the possible location of placental Ecuador, and therefore the area where we find the anastomosis.

As an alternative treatment if not available may be performed fetoscopia amniodrenaje aggressive. However, we must not forget that its role is palliative for the sole purpose of reducing the Polyhydramnios without acting on the cause of the disease.

The results of laser coagulation in experienced centers published in the last ten years ranging between 75 and $90 \%$ survival for at least one fetus [23-31]. The rate of serious neurological sequelae year of life hovers around 6\% [32], being in uncomplicated monochorionic twins 3-4\% [33, 34]. The amniodrenaje got worse results with survival of at least one fetus about $50 \%$ (31.35) and much higher rates consequences that reach $40 \%$ per year [36]. Feticide experience to treat TFFS is limited; in some studies [37], a co-twin survival of $87 \%$ in their series, but with $20 \%$ of premature rupture of membranes is described. As for the expectant management, there are small series, which have posted a progression rate between 10 and $46 \%$ in a recent meta-analysis [11], recommend expectant management, with weekly ultrasound monitoring in cases of TFFS in stage I and lower gestational age 26 weeks laser coagulation of anastomoses in stages II to IV, and amnioreduction or septosto-mine in TFFS over 26 weeks.

RCIUs incidence in our series was $9.7 \%$, similar to that described by Lewi et al., [19]. Possible options include management RCIUs expectant management with early termination of pregnancy if considered indicated, selective feticide if there is imminent risk of MFIU or RCIUs appears in previable age, or coagulation of anastomoses $[19,20]$.

The overall rate of prematurity was $64.5 \%, 100 \%$ for complicated monochorionic gestations and $35.5 \%$ in uncomplicated.
The overall survival rate was $83.9 \%$, with $54.5 \%$ for complicated monochorionic gestations and $100 \%$ for uncomplicated.

Comparing the survival rate and prematurity in complicated and uncomplicated pregnancies, a statistically significant difference $(p$ $<0.01$ ) with a contingency coefficient of 0.5 was found.

Different authors have proposed a frequency between 1 and 4 weeks follow-up diamniotics monochorionic pregnancies. In the absence of evidence of cost-effectiveness, due to the lack of clinical trials, ultrasound monitoring of monochorionic twins diamniotics uncomplicated at intervals of 2-3 weeks from 16 weeks of gestational age [11] is recommended, which must include at least the extent of abdominal circumference, fetal brain image, the measurement of MCV of the 2 amniotic sacs and Doppler umbilical artery from 24 weeks [11].

\section{Conclusion}

The diamniotics monochorionic pregnancies are a type of highrisk twin pregnancy associated with more complications and perinatal fetal death.

The presence or not of the same determine perinatal outcomes. Early diagnosis and treatment predict the evolution.

\section{References}

[1]. Blondel B, Kogan MD, Alexander GR, Dattani N, Kramer MS, et al., (2002) The impact of the increasing number of multiple births on the rates of preterm birth and low birthweight: an international study. Am J Public Health 92(8): 1323-1330.

[2]. Dunn A, Macfarlane A (1996) Recent trends in the incidence of multiple births and associated mortality in En-gland and Wales. Arch Dis Child Fetal Neonatal Ed 75(1): 10-19.

[3]. Derom R, Bryan E, Derom C, Keith L, Vlietinck R (2001) Twins, chorionicity and zygosity. Twin Res 4(3): 134-136.

[4]. Bajoria R, Kingdom J (1997) The case for routine determination of chorionicity and zygosity in multiple pregnancy. Prenat Diagn 17(13): 1207-1225.

[5]. Ville Y (1997) Monochorionic twin pregnancies: 'les liaisons dangereuses'. Ultrasound Obstet Gynecol 10(2): 82-85.

[6]. Sebire NJ, Snijders RJ, Hughes K, Sepulveda W, Nicolaides KH (1997) The hidden mortality of monochorionic twin pregnancies. Br J Obstet Gynaecol 104(10): 1203-1207.

[7]. Acosta-Rojas R, Becker J, Munoz-Abellana B, Ruiz C, et al., (2007) Twin chorionicity and the risk of adverse perinatal outcome. Int J Gynaecol Obstet 96(2): 98-102.

[8]. Ortibus E, Lopriore E, Deprest J, Vandenbussche FP, Walther FJ, et al., (2009) The pregnancy and long term neurodevelopmental outcome of monochorionic diamniotic twin gestations: a multicenter prospective cohort study from the first trimester onward. Am J Obstet Gynecol 200(5): 494. e1-494. e8.

[9]. Sebire N, Talbert D, Fisk NM (2001) Twin-to-twin transfusion syndrome results from dynamic asymmetrical reduction in placental anastomoses: a hypothesis. Placenta 22(5): 383-391.

[10]. Quintero RA, Morales WJ, Allen MH, Bornick PW, Johnson PK, et al., (1999) Staging of twin-twin transfusion syndrome. J Perinatol 19(8): 550- 
555

[11]. Moise, KJ, Johnson A (2011) Management of twin-twin transfusion syndrome. UpToDate,

[12]. Slaghekke F, Kist WJ, Oepkes D, Pasman SA, Middeldorp JM, et al., (2010) Twin anemiapolycythemia sequence: diagnostic criteria, classification, perinatal management and outcome. Fetal Diagn Ther 27(4): 181-190.

[13]. Valsky DV, Eixarch E, Martinez JM, Crispi F, Gratacós E (2010) Selective intrauterine growth restriction in monochorionic twins: pathophysiology, diagnostic approach and management dilemmas. Semin Fetal Neonatal Med 15(6): 342-348.

[14]. Gratacós E, Lewi L, Muñoz B, Acosta-Rojas R, Hernandez-Andrade E, et al., (2007) A classification system for selective intrauterine growth restriction in monochorionic pregnancies according to umbilical artery Doppler flow in the smaller twin. Ultrasound Obstet Gynecol 30(1): 28-34.

[15]. Glinianaia SV, RankinJ, Wright C (2008) Congenital anomalies in twins: a register-based study. Hum Reprod 23(6): 1306-1311.

[16]. Sepulveda W, Wong AE, Pons A, Jorge Gutiérrez P, Edgardo Corral S (2005) Secuencia de perfusión arterial reversa (gemelo acárdico): evaluación prenatal y tratamiento. Rev Chil Ultrasonog 8: 118-130.

[17]. Shetty A, Smith A (2005) The sonographic diagnosis of chorionicity. Prenat Diagn 25(9): 735-739.

[18]. Sepulveda W, Sebire NJ, Hughes K, Odibo A, Nicolaides KH (1996) The lambda sign at 10-14 weeks of gestation as a predictor of chorionicity in twin pregnancies. Ultrasound Obstet Gynecol 7(6): 421-423.

[19]. Lewi L, Lewi P, Diemert A, Jani J, Gucciardo L, et al., (2008) The role of ultrasound examination in the first trimester and at 16 weeks'gestation to predict fetal complications in monochorionic diamniotic twin pregnancies. Am J Obstet Gynecol 199(5): 493.e1-493.e7.

[20]. Fratelli N, Prefumo F, Fichera A, Valcamonico A, Marella D, et al., (2011) Nuchal translucency thickness and crown rump length discordance for the prediction of outcome in monochorionic diamniotic pregnancies. Early Hum Dev 87(1): 27-30.

[21]. Kagan KO, Gazzoni A, Sepulveda-Gonzalez G, Sotiriadis A, Nicolaides KH (2007) Discordance in nuchal translucency thickness in the prediction of severe twin-to-twin transfusion syndrome. Ultrasound Obstet Gynecol 29(5): 527-532.

[22]. Senat MV, Deprest J, Boulvain M, Paupe A, Winer N, et al., (2004) Endoscopic laser surgery versus serial amnioreduction for severe twin-to-twin transfusion syndrome. N Engl J Med 351(2): 136-144.

[23]. Rossi AC, D'Addario V (2008) Laser therapy and serial amnioreduction as treatment for twin-twin transfusion syndrome: a metaanalysis and review of literature. Am J Obstet Gynecol 198(2): 147-152.

[24]. Ville Y, Hecher K, Gagnon A, Sebire N, Hyett J, et al., (1998) Endoscopic laser coagulation in the management of severe twin-to-twin transfusion syndrome. Br J Obstet Gynaecol 105(4): 446-453.

[25]. Ierullo AM, Papageorghiou AT, Bhide A, Fratelli N, Thilaganathan B (2007) Severe twin-twin transfusion syndrome: outcome after fetoscopic laser ablation of the placental vascular equator. Bjog 114(6): 689-693.

[26]. Middeldorp JM, Sueters M, Lopriore E, Klumper FJ, Oepkes D, et al., (2007) Fetoscopic laser surgery in 100 pregnancies with severe twin-to-twin transfusion syndrome in the Netherlands. Fetal Diagn Ther 22(3): 190-194.
[27]. Robyr R, Boulvain M, Lewi L, Huber A, Hecher K, et al., (2005) Cervical length as a prognostic factor for preterm delivery in twin-to-twin transfusion syndrome treated by fetoscopic laser coagulation of chorionic plate anastomoses. Ultrasound Obstet Gynecol 25(1): 37-41.

[28]. Gratacós E, Van Schoubroeck D, Carreras E, Devlieger R, Roma E, et al., (2002) Impact of laser coagulation in severe twin-twin transfusion syndrome on fetal Doppler indices and venous blood flow volume. Ultrasound Obstet Gynecol 20(2): 125-130.

[29]. Quintero RA, Dickinson JE, Morales WJ, Bornick PW, Bermúdez C, et al., (2003) Stage-based treatment of twin-twin transfusion syndrome. Am J Obstet Gynecol 188(5): 1333-1340.

[30]. Quintero RA, Bornick PW, Allen MH, Johson PK (2001) Selective laser photocoagulation of communicating vessels in severe twin-twin transfusion syndrome in women with an anterior placenta. Obstet Gynecol 97(3): 477 481.

[31]. Hecher K, Plath H, Bregenzer T, Hansmann M, Hackelöer BJ (1999) Endoscopic laser surgery versus serial amniocenteses in the treatment of severe twin-twin transfusion syndrome. Am J Obstet Gynecol 180(3 Pt 1): 717 724.

[32]. Graef C, Ellenrieder B, Hecher K, Hackeloer BJ, Huber A, et al., (2006) Long-term neurodevelopmental outcome of 167 children after intrauterine laser treatment for severe twin-twin transfusion syndrome. Am J Obstet Gynecol 194(2): 303-308

[33]. Adegbite AL, Castille S, Ward S, Bajoria R (2004) Neuromorbidity in preterm twins $\mathrm{n}$ relation to chorionicity and discordant birth weight. Am J Obstet Gynecol 190(1): 156-163.

[34]. Bejar R, Vigliocco G, Gramajo H, Solana C, Benirschke K, et al., (1990) Antenatal origin of neurologic damage in newborn infants. II. Multiple gestations. Am J Obstet Gynecol 162(5): 1230-1236.

[35]. Mari G, Roberts A, Detti L, Kovanci E, Stefos T, et al., (2001) Perinatal morbidity and mortality rates in severe twin-twin transfusion syndrome: results of the International Amnioreduction Registry. Am J Obstet Gynecol 185(3): 708-715.

[36]. Denbow ML, Battin MR, Cowan F, Azzopardi D, Edwards AD, et al., (1998) Neonatal cranial ultrasonographic findings in preterm twins complicated by severe fetofetal transfusion syndrome. Am J Obstet Gynecol 178(3): 479-483.

[37]. Taylor MJ, Shalev E, Tanawattanacharoen S, Jolly M, Kumar S, et al., (2002) Ultrasound-guided umbilical cord occlusion using bipolar diathermy for Stage III/IV twin-twin transfusion syndrome. Prenat Diagn 22(1): 70-76.

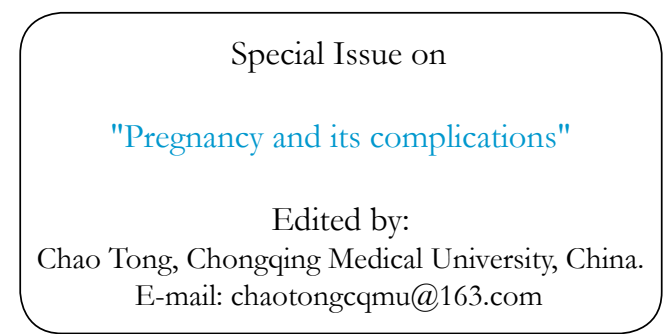

